\title{
New photosensitizers for photodynamic therapy in gastroenterology
}

\author{
SG Bown MD FRCP, AZ Rogowska MD
}

SG Bown, AZ Rogowska. New photosensitizers for photodynamic therapy in gastroenterology. Can J Gastroenterol 1999;13(5):389-392. Most applications of photodynamic therapy (PDT) in gastroenterology to date have used porfimer sodium as the photosensitizing agent. For destroying small lesions in the wall of the gastrointestinal tract in inoperable patients, it has proved to be most effective, but attempts to achieve circumferential mucosal ablation, as in the treatment of Barrett's esophagus, have led to a high incidence of strictures, and all patients have cutaneous photosensitivity, which can last up to three months. Two new photosensitizers are of particular interest to gastroenterologists. PDT with metatetrahydroxyphenyl chlorin produces a similar biological effect as PDT with porfimer sodium, but the light doses required are much smaller, and cutaneous photosensitivity lasts only two to three weeks. Further, it can be used with percutaneous light delivery to destroy localized pancreatic cancers. The photosensitizing agent 5 -amino levulinic acid, converted in vivo into the photoactive derivative protoporphyrin IX, sensitizes the mucosa much more than the underlying layers. This makes it feasible to destroy areas of abnormal mucosa without damaging the underlying muscle and is, therefore, better for treating Barrett's esophagus. Detailed clinical studies are required to establish the real role of PDT with the use of these and other new photosensitizers.

Key Words: 5-Amino levulinic acid; Barrett's esophagus; Metatetrahydroxyphenyl chlorin; Photodynamic therapy; Porfimer sodium

\section{Nouveaux agents photosensibilisants pour le traitement photodynamique en gastro-entérologie}

RÉSUMÉ : À ce jour, la plupart des indications du traitement photodynamique en gastro-entérologie ont porté sur l'emploi de Photofrin comme agent photosensibilisant. Il s'est révélé des plus efficaces pour la destruction des petites lésions dans la paroi des voies gastro-intestinales des patients inopérables,. Mais les tentatives d'ablation circonférentielle de la muqueuse pour le traitement de l'œsophage de Barrett ont donné lieu à un fort taux de strictures et tous les patients souffrent de photosensibilité cutanée qui peut durer jusqu'à trois mois. Deux nouveaux agents de photosensibilisation sont particulièrement intéressants pour les gastro-entérologues: le chlore de métatétrahydroxyphényle produit un effet biologique similaire à Photofrin, mais les doses de lumière nécessaires sont beaucoup moindres et la photosensibilité cutanée dure deux à trois semaines seulement. De plus, on peut l'utiliser avec l'administration d'une lumière percutanée pour détruire les cancers du pancréas localisés. L'autre agent photosensibilisant, l'acide 5-amino lévulinique converti in vivo en son dérivé photoactif protoporphyrine IX, sensibilise la muqueuse beaucoup plus que les souches sous-jacentes. Cela permet de détruire les zones de muqueuse anormale sans endommager le muscle sous-jacent et est par conséquent préférable pour le traitement de l'œsophage de Barrett. Des études cliniques détaillées s'imposent pour confirmer le rôle réel du traitement photodynamique au moyen de ces agents photosensibilisants et éventuellement, au moyen de nouveaux agents.
$\mathrm{P}$ hotodynamic therapy (PDT) has attracted considerable interest over the past few years as a way of producing localized tissue necrosis with light after administration of a photosensitizing agent (1). Interest has focused on the man- agement of small tumours because many photosensitizers are retained slightly more in cancers than in the surrounding tissue in which the cancer arose. There is no effect from either drug or light given alone, and the biological effect of the

National Medical Laser Centre, Institute of Surgical Studies, Royal Free and University College Medical School, London, United Kingdom

Correspondence: Dr Stephen G Bown, Director, National Medical Laser Centre, Charles Bell House, 67-73 Riding House Street, London, United Kingdom W1P 7LD. Telephone 171-504-9060, fax 171-813-2828, e-mail s.bown@ucl.ac.uk 
combination is quite different from that of most commonly used methods of localized tissue destruction. Tissue temperature does not increase; therefore, unlike diathermy and thermal laser treatments, there is remarkably little damage to connective tissues such as collagen and elastin. Further, unlike radiotherapy, there is no cumulative toxicity, so treatment can be repeated at the same site if necessary.

The mechanism of PDT is photochemical. Cytotoxicity is thought to be mediated by a highly reactive oxygen species, singlet oxygen, which destroys vital cell structures such as mitochondria (2). The main target may be parenchymal cells in a tumour being treated, but may also be macrophages or the microvasculature within a tumour, and this varies with the photosensitizer being used. The ideal photosensitizer should have a pure and stable chemical composition, have no dark toxicity, have a strong absorption peak in the red part of the visible spectrum (because this gives the best tissue penetration of light), be an efficient generator of singlet oxygen and cause minimum cutaneous photosensitivity.

Most of the development work on PDT until recently has been done with the photosensitizing agent hematoporphyrin derivative and its partly purified commercial preparation porfimer sodium (Photofrin, QLT Photo Therapeutics Inc, Vancouver, British Columbia). A great deal has been achieved with porfimer sodium, but unfortunately it has important drawbacks. These include a poorly defined chemical composition, prolonged skin photosensitivity (3) and poor photochemical properties because it only has a small absorption peak in the red region of the visible spectrum and, therefore, requires relatively long treatment times. Nevertheless, it is the only photosensitizer that has received regulatory approval in any country. The United States Food and Drug Administration and several governments in Europe have approved its use in the palliation of advanced esophageal cancers when there are no other treatment options. Nevertheless, there is considerable doubt about whether this is an appropriate indication because there is no convincing evidence that PDT can help patients if neodymium:yttrium-aluminum-garnet laser recanalization or stent insertion fails (4). On purely scientific grounds, the approval from the Japanese government for the treatment of early esophageal cancers is much more logical.

In theory, PDT is an attractive option for the treatment of Barrett's esophagus with dysplasia, and several groups have tried using PDT with porfimer sodium for this. It is possible to destroy the abnormal mucosa, but unfortunately this has been associated with a high incidence of later development of strictures (5). These are more difficult to dilate effectively than benign strictures from reflux esophagitis; with reflux esophagitis, the scarring is largely confined to the mucosal and submucosal layers, whereas with PDT the stricture is due to muscle scarring. PDT with 5-aminolevulinic acid (5-ALA) (Levulan, DUSA Pharmaceuticals Inc, Valhalla, New York) is much more promising, as discussed below.

The general promise of PDT, along with the specific problems associated with porfimer sodium, have stimulated research on the development of new photosensitizers. A wide range of 'second-generation' photosensitizers is being studied, including metallophthalocyanines, chlorins, purpurins, cationic dyes, porphycines, texaphyrins and other porphyrin derivatives such as the benzoporphyrin derivative monoacetate. The present article reviews the current situation with the two second-generation photosensitizers that have attracted the most interest in gastroenterology, namely metatetrahydroxyphenyl chlorin (m-THPC) (temoporfin, Foscan, Scotia Pharmaceuticals Ltd, Stirling, United Kingdom) and 5-ALA.

\section{m-THPC}

$\mathrm{m}$-THPC is a chlorin that was first synthesized at Queen Mary College, London, United Kingdom (6). It is chemically pure and stable, has a strong absorption peak in the red part of the spectrum at $652 \mathrm{~nm}$ (at which wavelength the light penetrates tissue slightly better than at the $630 \mathrm{~nm}$ required for porfimer sodium, so a deeper effect can be produced) and has a much higher singlet oxygen yield than porfimer sodium (7). This means that lower light doses are required (typically 10 to $20 \mathrm{~J} / \mathrm{cm}^{2}$, compared with porfimer sodium, for which the doses are usually over $100 \mathrm{~J} / \mathrm{cm}^{2}$ ), so treatment times can be shortened. Care must still be taken with skin sensitivity to bright lights, but this usually lasts two to three weeks rather than the two to three months associated with porfimer sodium. These characteristics make PDT with $\mathrm{m}$-THPC technically easier and more comfortable for patients.

Most of the initial work with m-THPC focused on early invasive cancers of the mouth and showed that the clinical effect is comparable with that seen using porfimer sodium but that it can be achieved with much lower light doses and a shorter duration of skin photosensitivity (8). There are no data on PDT with m-THPC for palliating advanced esophageal cancers, for the simple reason that none of the groups currently working with this drug believes that this is an appropriate indication for PDT. The best results on the treatment of early esophageal cancers are from the Swiss group in Lausanne (9). Twenty-eight patients with early bronchial or esophageal cancers (carcinoma in situ or microinvasive) were treated with $\mathrm{m}$-THPC-mediated PDT, and this eradicated $77 \%$ of the tumours. Skin photosensitivity was only seen during the first week after injection, although one esophageal fistula, one bronchial stenosis and two possible occult esophageal perforations were seen. This led the group to suggest that it might be better to use green light for these early lesions (green light penetrates less than red, and $\mathrm{m}$-THPC also absorbs in this part of the spectrum) to minimize the risk of muscle damage and perforation.

The same Swiss group recently reviewed their results with $\mathrm{m}$-THPC on early esophageal cancers to try to identify reasons for treatment failure. This is the first time that this has been done systematically for any photosensitizer. The main causes were understaging of the tumour, inadequate light delivery to all relevant areas and a low tumour concentration of $\mathrm{m}$-THPC (10). These results should help to improve treatment techniques in the future. 


\section{5-ALA}

The other photosensitizing agent that is attracting considerable interest in gastroenterology is 5-ALA (11). In contrast to $\mathrm{m}$-THPC, which was synthesized in the laboratory, 5ALA is a naturally occurring precursor of heme, which is produced in every nucleated cell. Normally, the production of 5-ALA is controlled by negative feedback inhibition depending on the local concentration of heme. However, following the administration of an excess of exogenous 5-ALA, the natural regulatory mechanism is bypassed, and the heme biosynthesis pathway is overloaded. The rate-limiting step then becomes the final conversion of protoporphyrin IX (PPIX) to heme, which is catalyzed by ferrochelatase. As a result, PPIX, which is a photosensitizer in its own right, accumulates in cells, although the excess PPIX is metabolized to heme within a few hours, so the skin photosensitivity only lasts one to two days, in contrast to weeks or even months with other agents. 5-ALA can be given topically or by mouth (11).

The tissue distribution of PPIX, the photoactive derivative of 5-ALA, is quite different from that of most other photosensitizers such as m-THPC and porfimer sodium. In hollow organs such as the gastrointestinal tract, PPIX is found predominantly in the mucosa. This makes it possible to achieve selective mucosal necrosis without damaging the underlying muscle (12). This is very difficult with porfimer sodium because the drug is localized predominantly in the microvasculature in the submucosa (13) and because illumination causes microvascular shutdown, which leads to necrosis of all layers. The tissue distribution of $\mathrm{m}$-THPC falls between that of PPIX and porfimer sodium. With m-THPC, there is drug in the mucosa and submucosa (14). If red light, which penetrates to all layers, is used, full thickness necrosis is likely, but with less penetrating green light it is possible to limit the effect to the superficial layers.

PDT damage that does not affect the muscularis propria heals remarkably well by regeneration, with little, if any, scarring. This makes PDT with 5-ALA particularly attractive for treating areas of circumferential, superficial disease, such as Barrett's esophagus. Several clinical trials have reported that PDT with 5-ALA can eradicate dysplasia in Barrett's mucosa and reduce the length of the segment with columnar epithelium $(15,16)$. No side effects were observed, in contrast to the high incidence of esophageal strictures seen in studies using porfimer sodium (5). However, PDT with 5-ALA, as it is currently used, may not be sufficient treatment. In several studies, persistent columnar epithelium has been detected underneath regenerated squamous mucosa $(15,16)$. The implications of this are not yet clear, but it does raise the question of whether the treatment is adequate. Long term studies are needed to assess the importance of this residual columnar epithelium.

PDT with 5-ALA can eradicate some early esophageal cancers, but only those that are no deeper than $2 \mathrm{~mm}$ (16). Attempts to use PDT with 5-ALA for the treatment of more bulky polyps or carcinomas have been unsuccessful (17). The oral dose of 5 -ALA of $60 \mathrm{mg} / \mathrm{kg}$ is limited by nausea and hepatotoxicity, thought to be due to first pass metabolism of the drug. One way of overcoming this may be to give the drug intravenously. Other options that have been shown in animal studies to enhance the effect are to use 5-ALA esters (18), to add an iron chelator (which slows down the conversion of PPIX to heme) (19) or to fractionate the light dose (20).

\section{PDT FOR ORGANS OUTSIDE THE LUMINAL GUT}

Although most applications of PDT have been on lesions in hollow organs, there is an increasing interest in its use for the treatment of lesions in solid organs. For gastroenterologists, the target of most interest is the pancreas. A lot of experimental work has been undertaken, mainly in hamsters, to study the PDT effects on tumours transplanted into the pancreas and on the surrounding normal tissues. The photosensitizers used were porfimer sodium, aluminum sulphonated phthalocyanine, pheophorbide A, 5-ALA and $\mathrm{m}$-THPC $(21,22)$. The results were broadly the same with all of the photosensitizers. Necrosis occurred in the tumour and in surrounding normal tissues (pancreas, stomach, duodenum and bile duct) if they were exposed to the light, but this healed safely in all organs except the duodenum, in which some perforations were seen. In a randomized, controlled study on implanted pancreatic cancers in hamsters treated with PDT with 5-ALA, tumour necrosis up to $8 \mathrm{~mm}$ deep was achieved, and there was a significant increase in the survival time of treated animals compared with that of untreated controls (23). This was unexpected because the effect with 5-ALA has been shown to be so superficial in other parts of the gastrointestinal tract.

Clinical studies have only been reported using $\mathrm{m}$-THPC (24). This photosensitizer was chosen for the same reason as outlined above - the area of necrosis around each treatment site was largest and the light doses required were the smallest. Three days after the intravenous administration of the drug, up to four laser fibres for light delivery were inserted into the tumour through needles positioned percutaneously under computed tomography (CT) guidance. Only 12 patients with small cancers localized to the pancreas have been treated, but the results are encouraging. The treatment was well tolerated, and there were no serious complications. Most patients tolerated oral nutrition by two days after treatment, and none developed pancreatitis. Zones of necrosis up to $6.5 \mathrm{~cm}$ in diameter were documented on contrastenhanced CT scans taken a few days after treatment. A duodenal stricture developed several months later in one patient, but at the time of reporting, seven patients were still alive - two more than one year (16 and 17 months, respectively) after treatment. The others died four, six, six, seven and 16 months, respectively, after treatment. These preliminary results suggest that the technique is feasible and safe, although larger scale studies are needed to assess the role of PDT in the management of pancreatic cancer. Endoscopic PDT for tumours of the ampulla of Vater and biliary tree may also have considerable potential. This has been reported with the use of porfimer sodium (25). 
There are other applications of PDT on the horizon in gastroenterology that may require a range of different photosensitizers. In theory, PDT is an attractive option as adjuvant therapy after surgery to destroy any microscopic tumour deposits that may have been left behind. A randomized, controlled study that applied PDT with porfimer sodium to the tumour bed after resection of rectosigmoid cancers was reported; unfortunately, no improvement in either the local recurrence rate or patient survival in the PDT-treated group was seen (26). m-THPC looks encouraging for adjunctive therapy in animal studies (27), but no clinical results are yet available.

A more speculative application is the use of PDT to kill Helicobacter pylori. In culture, this can be done very easily with a range of photosensitizers, of which perhaps the simplest and most interesting is methylene blue (28). In theory, all the sites in the upper gastrointestinal tract colonized by $\mathrm{H}$ pylori are accessible to topical application of a photosensi-

\section{REFERENCES}

1. Dougherty TJ, Gomer CJ, Henderson BW, et al. Photodynamic therapy. J Natl Cancer Inst 1998;90:889-905.

2. Weishaupt KR, Gomer CJ, Dougherty TJ. Identification of singlet oxygen as the cytotoxic agent in the photoactivation of a murine tumour. Cancer Res 1976;36:2326-9.

3. Dougherty TJ, Cooper MT, Mang TS. Cutaneous phototoxic occurrences in patients receiving Photofrin. Lasers Surg Med 1990;10:485-8.

4. Bown SG, Millson CE. Photodynamic therapy in gastroenterology. Gut 1997;41:5-7.

5. Overholt B, Panjehopur M. Photodynamic therapy for Barrett's esophagus: clinical update. Am J Gastroenterol 1996;91:1719-23.

6. Bonnett R, White R, Winfield U-J. Hydroporphyrins of the meso-tetra (hydroxyphenyl) porphyrin series as tumour photosensitizers. Biochem J 1989;261:277-80.

7. Ma L, Moan J, Berg K. Evaluation of a new photosensitizer, meso-tetra-hydroxyphenyl chlorin for use in photodynamic therapy: a comparision of its photobiological properties with those of two other photosensitizers. Int J Cancer 1994;57:883-8.

8. Fan KFM, Hopper C, Speight PM, Buonaccorsi GA, Bown SG. Photodynamic therapy using $\mathrm{mTHPC}$ for malignant disease in the oral cavity. Int J Cancer 1997;73:25-32.

9. Grosjean P, Savary J-F, Mizeretet J. Tetra (m-hydroxyphenyl) chlorin clinical photodynamic therapy of early bronchial and oesophageal cancers. Laser Med Sci 1996;11:227-35.

10. Grosjean P, Wagnieres G, Fontolliet C, van der Bergh H, Monnier P. Treatment failures after Foscan and $514 \mathrm{~nm}$ light for early squamous cell carcinomas in the esophagus. International Photodynamic Association, 7th Biennial Congress. Nantes, July 7-9 1998.

11. Kennedy JC, Pottier RH. Endogenous protoporphyrin IX, a clinically useful photosensitizer for photodynamic therapy. J Photochem Photobiol B 1992;14:275-92.

12. Loh CS, MacRobert AJ, Buonaccorsi G, Krasner N, Bown SG. Mucosal ablation using photodynamic therapy for the treatment of dysplasia - an experimental study in the normal rat stomach. Gut 1996;38:71-8.

13. Bugelski PJ, Porter CW, Dougherty TJ. Autoradiographic distribution of $\mathrm{HpD}$ in normal and tumour tissue of the mouse. Cancer Res 1981;41:4606-12.

14. Mlkvy P, Messman H, Pauer M, et al. Distribution and photodynamic therapy effects of $\mathrm{mTHPC}$ in the pancreas and adjacent tissues in the syrian golden hamster. Br J Cancer 1996;73:1473-9.

15. Barr H, Shepherd NA, Dix A, Roberts DJ, Tan WC, Krasner N. Eradication of high grade dysplasia in columnar lined Barrett's tizer and to endoscopic light delivery, although it would be a major technical challenge to achieve this in practice.

\section{CONCLUSIONS}

PDT has considerable potential in gastroenterology, but no application is fully established. New photosensitizers such as $\mathrm{m}$-THPC look promising for small lesions in the wall of the gastrointestinal tract in patients who are unsuitable for surgery and for new applications, as in the pancreas and biliary tract. 5-ALA holds out the exciting possibility of selective mucosal necrosis, leaving the underlying muscle unaffected, which may be of value in the management of Barrett's esophagus and perhaps lesions further down the gastrointestinal tract. However, many careful studies need to be done to establish the true role of PDT in gastroenterology and to see which photosensitizers are most appropriate for each application.

oesophagus by photodynamic therapy with endogenously generated protoporphyrin IX. Lancet 1996;384:584-5.

16. Gossner L, Stolte M, Sroka R, et al. Photodynamic ablation of high-grade dysplasia and early cancer in Barrett's esophagus by means of 5-aminolaevulinic acid. Gastroenterology 1998;114:448-55.

17. Regula J, MacRobert AJ, Gorchein A, et al. Photosensitisation and photodynamic therapy of oesophageal, duodenal, and colorectal tumours using 5 aminolaevulinic acid induced protoporphyrin IX a pilot study. Gut 1995;36:67-75.

18. Peng Q, Moan J, Warloe T, et al. Build-up of esterified aminolevulinic acid derivative induced porphyrin fluorescence in normal mouse skin. J Photochem Photobiol B 1996;34:95-6.

19. Curnow A, McIlroy BW, Postle-Hacon MJ, Porter JB, MacRobert AJ, Bown SG. Enhancement of 5-aminolaevulinic acid induced photodynamic therapy in normal rat colon using hydroxypyridinone iron chelating agents. Br J Cancer 1998;78:1278-82.

20. Messman H, Mlkvy P, Buonaccorsi G, Davies CL, MacRobert AJ, Bown SG. Enhancement of photodynamic therapy with 5-aminolaevulinic acid induced porphyrin photosensitisation in normal rat colon by threshold and light fractionation studies. Br J Cancer 1995;72:589-94.

21. Everard S, Keller P, Hajri A, et al. Experimental pancreatic cancer in the rat treated by photodynamic therapy. Br J Surg 1994;81:1185-9.

22. Mlkvy P, Messman H, MacRobert AJ, et al. Photodynamic therapy of a transplanted pancreatic cancer model using metatetrahydroxyphenyl chlorin (mTHPC). Br J Cancer 1997;76:713-8.

23. Regula J, Ravi B, Bedwell J, MacRobert AJ, Bown SG. Photodynamic therapy using 5-aminolaevulinic acid for experimental pancreatic cancer - prolonged animal survival. Br J Cancer 1994;70:248-54.

24. Rogowska AZ, Whitelaw DE, Lees WR, et al. Photodynamic therapy for palliation of unresectable pancreatic cancer. Gut 1999;44 (Suppl 1):A48. (Abst)

25. Abulafi AM, Allardice JT, Williams NS, van Someren N, Swain CP, Ainley CA. Photodynamic therapy for malignant tumours of the ampulla of Vater. Gut 1995;36:853-6.

26. Ansell JK, Abulafi AM, Allardice JT, de Jode ML, Grahn MF, Williams NS. Adjuvant intraoperative photodynamic therapy for colorectal cancer. Br J Surg 1996;83:694. (Abst)

27. Abulafi AM, deJode MJ, Allardice J. Adjuvant intraoperative photodynamic therapy in experimental colorectal cancer using a new photosensitiser. Br J Surg 1997;84:368-71.

28. Millson CE, Wilson M, MacRobert AJ, Bedwell J, Bown SG. The killing of Helicobacter pylori by low power laser light in the presence of a photosensitiser. J Med Microbiol 1996;44:245-52. 


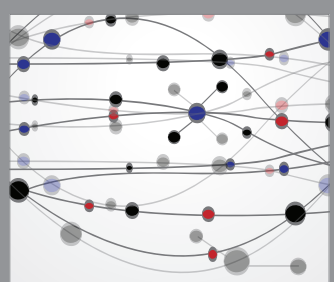

The Scientific World Journal
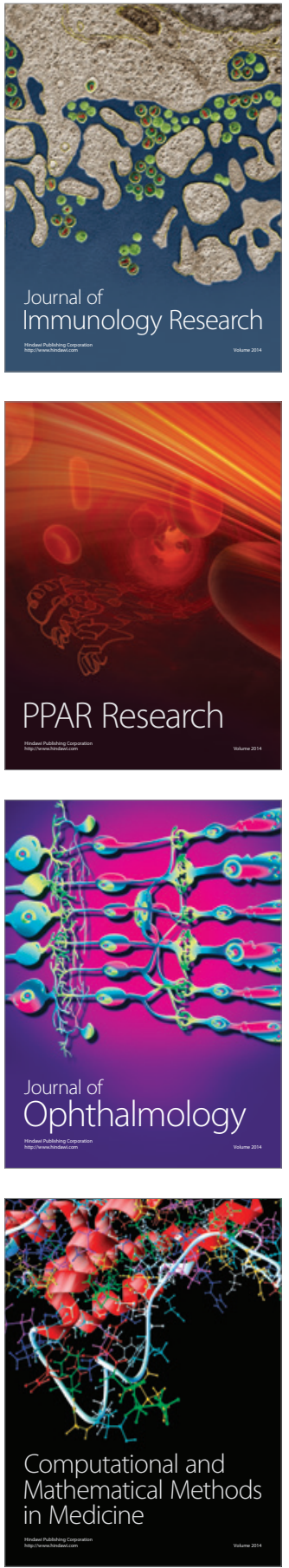

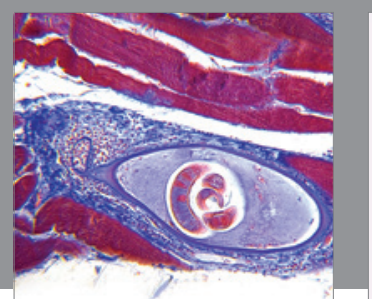

Gastroenterology Research and Practice

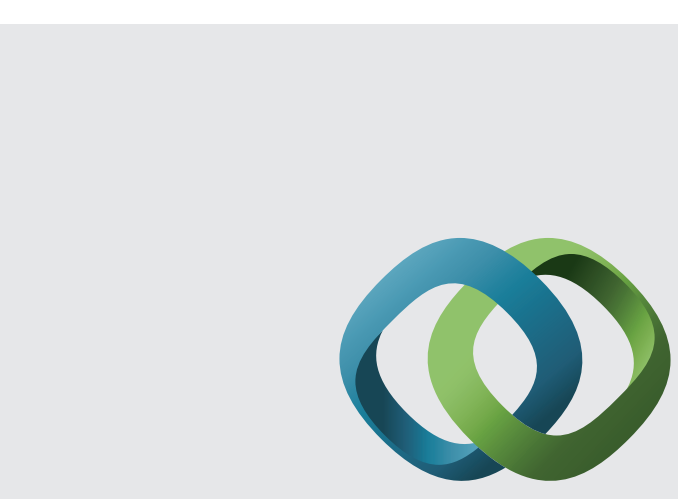

\section{Hindawi}

Submit your manuscripts at

http://www.hindawi.com
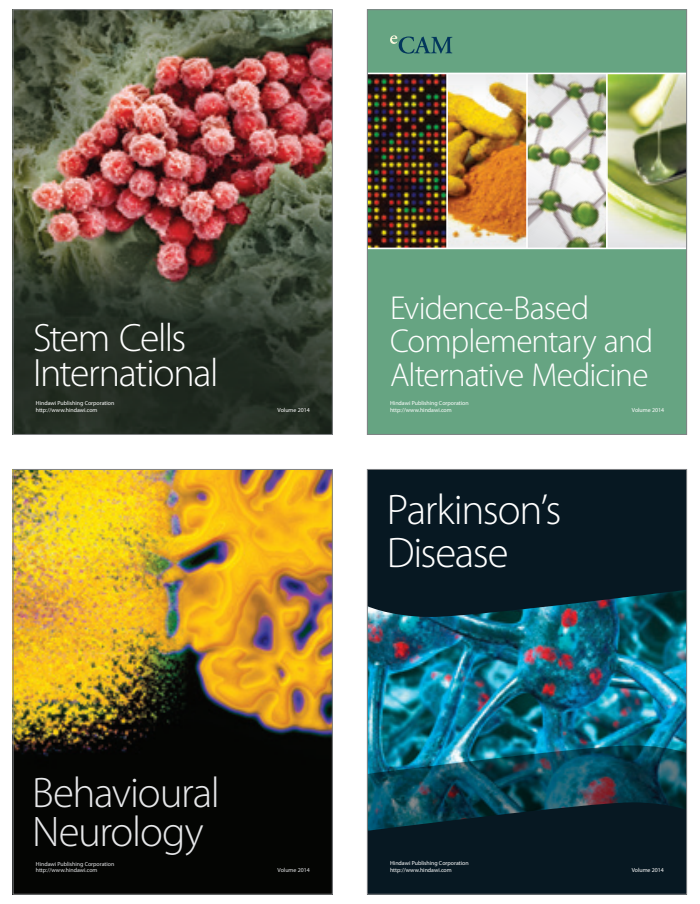
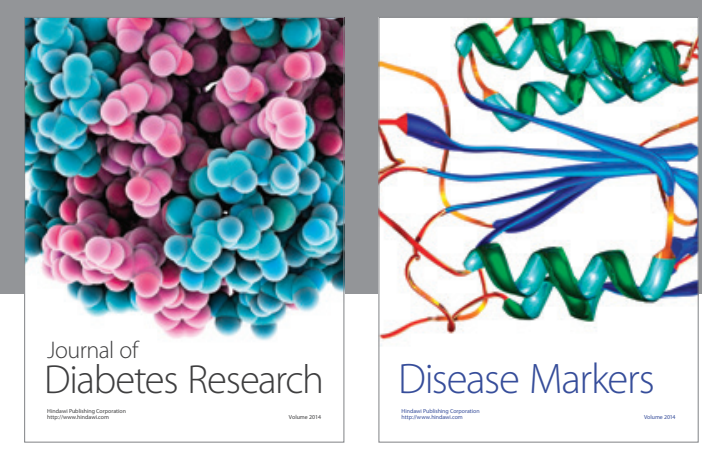

Disease Markers
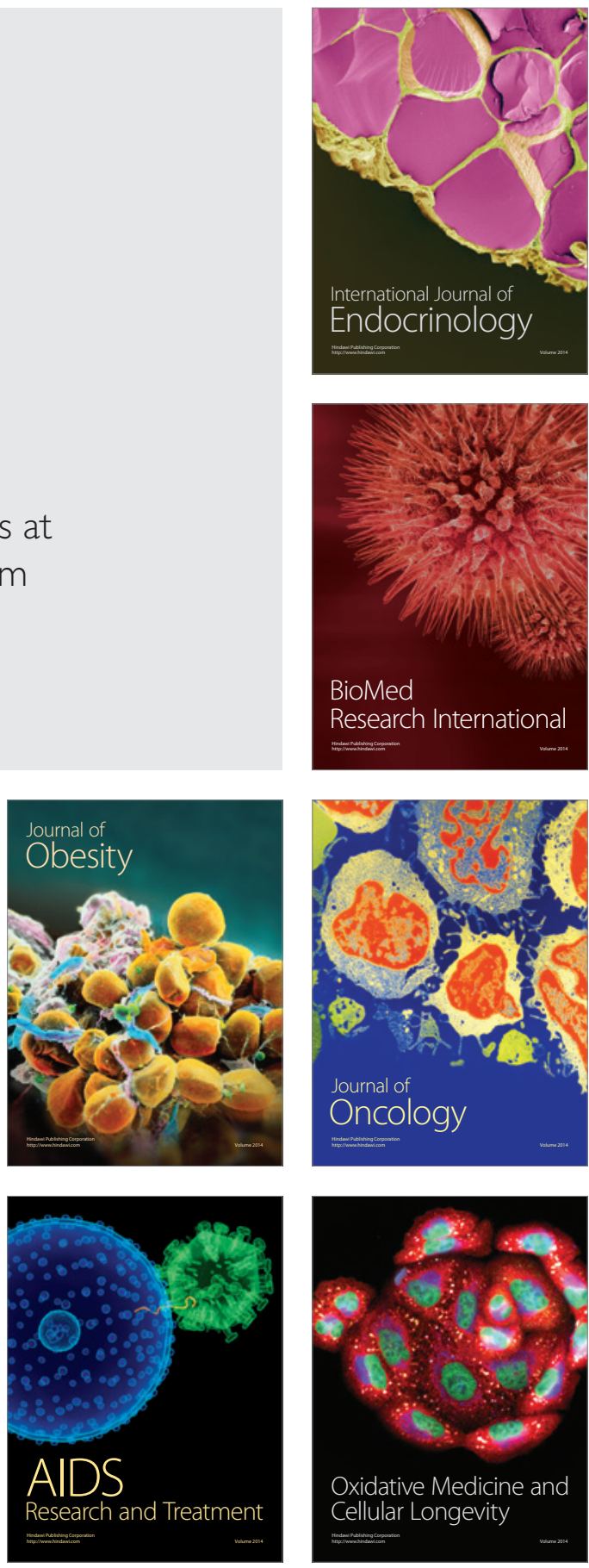